University of Nebraska - Lincoln

DigitalCommons@University of Nebraska - Lincoln

April 2007

\title{
Child abuse in the eyes of the beholder: Lay perceptions of child sexual and physical abuse
}

\author{
Brian H. Bornstein \\ University of Nebraska-Lincoln, bbornstein2@unl.edu \\ Debra L. Kaplan \\ University of Nebraska-Lincoln \\ Andrea R. Perry \\ University of Nebraska-Lincoln
}

Follow this and additional works at: https://digitalcommons.unl.edu/psychfacpub

Part of the Psychiatry and Psychology Commons

Bornstein, Brian H.; Kaplan, Debra L.; and Perry, Andrea R., "Child abuse in the eyes of the beholder: Lay perceptions of child sexual and physical abuse" (2007). Faculty Publications, Department of Psychology. 325.

https://digitalcommons.unl.edu/psychfacpub/325

This Article is brought to you for free and open access by the Psychology, Department of at DigitalCommons@University of Nebraska - Lincoln. It has been accepted for inclusion in Faculty Publications, Department of Psychology by an authorized administrator of DigitalCommons@University of Nebraska - Lincoln. 


\title{
Child abuse in the eyes of the beholder: Lay perceptions of child sexual and physical abuse
}

\author{
Brian H. Bornstein, Debra L. Kaplan, and Andrea R. Perry \\ Department of Psychology, University of Nebraska-Lincoln, Lincoln, NE, USA \\ Corresponding author: B. H. Bornstein
}

\begin{abstract}
Objective: The purpose was to explore the effects of victim and perpetrator gender, type of abuse, and victim-perpetrator relationship on university students' and non-students' perceptions of different kinds of child abuse.

Method: One hundred and ninety-nine participants (including university students and non-student adults) evaluated each of 24 vignettes (within-subjects design) describing an abusive interaction between a child and an adult. The following four variables were manipulated: the victim's gender, the perpetrator's gender, the type of abuse (physical, relatively mild sexual, or relatively severe sexual), and the perpetrator's relationship to the victim (parent or babysitter). Participants rated each vignette on a number of dimensions: degree of trauma and severity, likelihood of general occurrence and reoccurrence, victim believability, and "repressibility" of the event.

Results: Significant interactions emerged on each dimension. For example, sexual abuse (whether mild or severe) was rated as being more traumatic and severe if perpetrated by a parent, but relationship type did not affect perceptions of physical abuse. In addition, significant perpetrator gender by victim gender interactions indicated that homosexual abuse was perceived as more traumatic and repressible than heterosexual abuse, but as less likely to occur; and male participants tended to be more affected by the gender of the perpetrator and abuse type than female participants.

Conclusion: The results suggest that people have stereotypes about the circumstances and consequences of child abuse. These stereotypes are often, though not always, consistent with existing empirical findings.
\end{abstract}

Keywords: child abuse, lay perceptions, physical abuse, sexual abuse 


\section{Introduction}

The rates of child maltreatment vary based on how child maltreatment is defined, ranging from 11.9 per 1000 to 49.1 per 1000 children in the United States (Sedlak \& Broadhurst, 1996; US Department of Health and Human Services [USDHHS], 2006). Researchers also have reported that perceptions of child sexual abuse (CSA) vary according to characteristics of the case (Broussard, Wagner, \& Kazelskis, 1991; Dollar, Perry, Fromuth, \& Holt, 2004). For example, Broussard et al., in a study examining college students' perceptions of out-of-court cases of sexual abuse, asked participants to evaluate sexual abuse vignettes, which varied by perpetrator gender, victim gender, and victim response (encouraging, passive, or resisting), in terms of the extent to which they represented CSA. Participants viewed abuse of a male by a female as less indicative of abuse and less harmful to the victim than other gender combinations. Dollar et al. obtained similar findings in the context of students' perceptions of a teacher-student sexual experience.

Both studies found that homosexual abuse was perceived as more serious than heterosexual abuse, especially when the victim was male. Although a number of studies have measured perceptions of sexual abuse, those including other forms of maltreatment (e.g., physical abuse) are less prevalent. In contrast to the relatively consistent gender findings in sexual abuse research, research on perceptions of physical abuse has found no evidence that participants' ratings were influenced by victim or perpetrator gender (Dukes \& Kean, 1989).

Such lay perceptions regarding the nature of abuse, particularly sexual abuse, can matter in a number of respects, in that they are likely to influence victims' interactions with legal and mental health professionals, as well as peers and ordinary "others." Legal authorities might find an allegation of abuse more or less credible depending on the allegation's particular characteristics. For example, Hetherton and Beardsall (1988) found that child protection professionals (social workers and police) were more likely to recommend case registration and imprisonment for the offender when the sexual abuse was perpetrated by a male than by a female, suggesting that they perceived the former type of abuse as more serious.

Further down the legal road, case characteristics can influence a case's disposition at trial. Mock jurors' judgments in abuse cases are influenced by the victim and/or perpetrator's gender, often in interaction with other variables (Bornstein \& Muller, 2001; Clark \& Nightingale, 1997; ForsterLee, Horowitz, Ho, ForsterLee, \& McGovern, 1999). For example, Bornstein and Muller, in a mock jury study, found that an alleged sexual abuse victim's testimony of repressed/recovered memory was less credible and was associated with lower perceptions of the defendant's culpability than a condition in which the victim had remembered the abuse all along, but only in instances of heterosexual abuse; the victim's testimony exerted no effect in instances of homosexual abuse. If homosexual abuse is indeed perceived as more harmful to the victim (e.g., Dollar et al., 2004; Maynard \& Wiederman, 1997), then it follows that mock jurors would view such events as more "repressible." For physical abuse, although gender did not appear to have a substantial impact in the Dukes and Kean (1989) study, the authors found that physical abuse was perceived as being the most abusive (in comparison to psychological abuse and neglect), yet was rated as less likely to be reported than neglect. Thus, as with sexual abuse, influences due to others' perception of the incident-such as whether to report-may have lasting influences on child victims and their short- and long-term trajectory.

Within a therapeutic context, therapists' expectations can exert a powerful influence on their diagnosis and handling of individual cases (Elstein, 1988). Thus, therapists' stereotypes about abuse could 
affect their clinical disposition of such cases, in the same manner that expectations influence professionals' intervention recommendations (DeRoma, Hansen, Tishelman, \& D’Amico, 1997; Hetherton \& Beardsall, 1988). For instance, sexual abuse perceived as more severe (e.g., homosexual as opposed to heterosexual) could lead the therapist to adopt a more intensive or different style of treatment. Finally, laypersons' perceptions of abuse in general are likely to influence their response to individual instances of abuse. The ways in which people such as teachers, peers, and family members react to a child's disclosure of abuse can play a significant role in the child's interactions with support providers and subsequent adjustment (e.g., Kouyoumdjian, Perry, \& Hansen, 2005; Nagel, Putnam, Noll, \& Trickett, 1997).

\section{Aims and hypotheses}

As discussed, people have stereotypes about the circumstances and consequences of child abuse, and these expectancies can influence their judgments (legal or otherwise) about individuals (both victims and perpetrators) involved in abuse cases. The present study extends previous findings by addressing laypersons' (including students' and non-students') perceptions of abuse as a function of the gender of the victim, gender of the perpetrator, the relationship between victim and perpetrator, and the type/severity of abuse. Previous research (e.g., Dollar et al., 2004) focusing on perceptions of abuse has held the type of abuse and relationship between victim and perpetrator constant. Given that the actual incidence of abuse varies widely in terms of these characteristics, we sought to fill this gap in the literature by experimentally manipulating the factors of abuse type (i.e., mild sexual, severe sexual, or physical) and relationship (i.e., parent or babysitter). The two forms of sexual abuse were the primary focus of the study; the physical abuse scenario was included for more exploratory purposes.

An additional aim of this study was to assess participants' perceptions of various aspects of the abuse. Specifically, participants rated vignettes that varied four factors-victim and perpetrator gender, type of abuse, and victim/perpetrator relationship-along a number of abuse-related dimensions: perceived trauma to the victim, severity, likelihood of occurrence and reoccurrence, victim believability, and likelihood that the abuse would be repressed ("repressibility"). We present hypotheses for main effects first, followed by interactions that qualify these effects, and finally correlations among the different dimensions.

Participant characteristics: Previous research has shown that women are more sympathetic to sexual abuse victims, and find them more credible, than men (e.g., Golding, Fryman, Marsil, \& Yozwiak, 2003; Schmidt \& Brigham, 1996). Findings related to participant gender and ratings of physical abuse are more mixed, with some research revealing an effect (Kean \& Dukes, 1991) and some reporting no significant findings (Ashton, 2004). Based on this research as a whole, we predicted that women would rate the vignettes higher (e.g., more traumatic, more severe, etc.) than men on all dimensions. As prior research has not compared the perceptions of students and non-students, we made no hypotheses regarding participant type.

Victim gender: Even though the sequelae of abuse are similar for girls and boys (Kendall-Tackett, Williams, \& Finkelhor, 1993), people's perceptions of abuse often differ based on the gender of the victim. For example, female victims usually (though not always; see Bottoms \& Goodman, 1994) are perceived as more credible than males. Thus, we predicted, based on stereotypes of girls' vulnerability relative to boys' (e.g., Hicks \& Tite, 1998), that abuse of a female victim would be perceived as more 
traumatic, severe, and repressible, and that female victims would also be more believable (Clark \& Nightingale, 1997). Because sexual abuse of females is considerably more common in the United States than sexual abuse of males (though overall, maltreatment of boys and girls is roughly evenly split; USDHHS, 2006), we also predicted that it would be judged more likely to occur and to reoccur.

Perpetrator gender: Just as the literature emphasizes female victims, greater attention is paid to male perpetrators of sexual abuse, who appear to be more common (Cupoli \& Sewell, 1988), than to female perpetrators (Lewis \& Stanley, 2000). In contrast, overall abuse is perpetrated as much or more by mothers (40.8\%) than by fathers (18.8\%; McDonald, 2005). Here, we predicted that participants would perceive abuse by males as more likely to occur and reoccur, especially for sexual abuse. As abuse by male and female perpetrators does not differ in actual severity (Rudin, Zalewski, \& Bodmer-Turner, 1995), we did not expect it to differ in perceived severity, trauma, victim credibility, or repressibility.

Type of abuse: Based on the popular and documented (e.g., Kendall-Tackett et al., 1993) belief that the more extreme the abuse, the more harmful, we predicted that severe sexual abuse would be perceived as most traumatic and severe. In light of the Freudian notion that the more traumatic an event, the more likely it is to be repressed (Erdelyi, 1985), we also predicted that severe sexual abuse would be judged most repressible. Finally, because relatively severe abuse is statistically less common than other forms of abuse (USDHHS, 2006), we predicted that it would be judged less likely to occur and reoccur. The relationship between abuse type and victim believability could go in either direction. On the one hand, a claim of more severe abuse might be less plausible simply by virtue of being less common; yet on the other hand, the greater seriousness and consequences (for both the alleged perpetrator and victim) of a claim of more severe abuse might lead to greater belief in a claim of severe abusethat is, one would be less likely to make up something like that. Thus, we did not hypothesize an effect of abuse type on victim believability.

The hypotheses delineated above relate primarily to severe sexual abuse; it is less clear what to expect regarding the comparison of mild sexual abuse (operationalized as fondling) to physical abuse (beating with a belt). Both are quite common (USDHHS, 2006), and both can vary considerably in terms of other characteristics (e.g., invasiveness, duration). This comparison was, therefore, more exploratory in nature.

Relationship: Numerous studies have examined perceptions of abuse committed by a non-family member, such as a teacher (e.g., Dollar et al., 2004; Smith, Fromuth, \& Morris, 1997) or a neighbor (e.g., Back \& Lips, 1998). Because the impact of CSA increases the closer the relationship is between perpetrator and victim (Kendall-Tackett et al., 1993), as does the probability that it will not be recalled (Williams, 1994), the current study varied the relationship in order to compare the perceived impact of abuse committed by a family member (parent) to abuse by a non-family member (babysitter). It was predicted that parental abuse would be perceived as more traumatic, severe, and repressible than abuse by a babysitter. Statistically, the perpetrator of abuse is most likely to be a close relative, such as a parent (USDHHS, 2006 and Rudin et al., 1995); we, therefore, predicted that parental abuse would be perceived as relatively more likely to occur and reoccur. As with the type of abuse, the more traumatic level of this variable-that is, parental abuse-could make the victim seem either more or less believable compared to the (predicted) less traumatic level of babysitter abuse. 
Interactions: Although male perpetrator/male victim abuse scenarios are in some instances viewed more negatively than female perpetrator/female victim vignettes (Dollar et al., 2004), previous research has strongly suggested that same-sex abuse scenarios in general are often perceived as more abusive (Maynard \& Wiederman, 1997) than opposite-sex scenarios. Thus, we predicted a perpetrator gender by victim gender interaction, specifically that homosexual abuse would be perceived as more traumatic, severe, and repressible than heterosexual abuse. Because heterosexual abuse is more common, especially for male perpetrators (Faller, 1987 and Rudin et al., 1995), we also predicted an interaction between perpetrator and victim gender on ratings of the likelihood of occurrence and reoccurrence. Additionally, we hypothesized that sexual abuse perpetrated by a parent would be perceived as more traumatic, severe, and repressible than other scenarios (perpetrator type by abuse type). Finally, based on previous literature (e.g., Dollar et al., 2004), we predicted that male participants would be more affected by characteristics of the vignettes (e.g., perpetrator's gender, victim's gender) than female participants. Although we did not specifically hypothesize about the nature of other interactions, because abuse perceptions are moderated by a complex interplay of factors (e.g., Bornstein \& Muller, 2001; Broussard et al., 1991), we included all two-way interactions in the statistical models for exploratory purposes.

Correlations: Fundamental to the notion of repression is the idea that the memories/events most likely to be repressed are those that are most traumatic for the individual (Erdelyi, 1985). We consequently predicted a positive correlation among perceptions of trauma, severity, and repressibility. The laws of probability dictate that events that are more common in general should be more likely to reoccur in particular situations, so we also predicted a positive correlation between estimates of occurrence and reoccurrence. Although we had no specific hypotheses for how perceptions of the victim's credibility would be related to other measures, because of the importance of the victim's credibility in a variety of situations-treatment, the courtroom, and so forth-we explored correlations involving perceptions of the victim's believability.

\section{Method}

\section{Participants}

Undergraduate psychology students from a large Midwestern university received extra course credit for their participation. To generate a broader sample, each undergraduate was asked to recruit one non-student adult into the study ( $c f$ Fulero \& Finkel, 1991). The sample was comprised of 199 adults, 99 undergraduates $(M$ age $=20.6, M d n$ age $=19,78 \%$ female $)$ and 100 non-students $(M$ age $=33.3$, $M d n$ age $=25,56 \%$ female; one student returned a non-student questionnaire but not his or her own). The high proportion of women in the undergraduate sample reflects the composition of students taking psychology classes.

\section{Design}

The claims of abuse varied in four different respects: victim's gender, perpetrator's gender, perpetrator's relationship to the victim (parent or babysitter), and type of abuse (mild sexual abuse, severe sexual abuse, or physical/nonsexual abuse), resulting in a $2 \times 2 \times 2 \times 3$ within-subjects design. 
Table 1. Sample vignette

Mild/severe sexual abuse conditions. Helen [Rick], age 8, has been very moody over the past 6 months and her parents were concerned about her. They sent Helen to see a psychotherapist whom she has been seeing once a week on a regular basis. This week she told her therapist that she was abused one time by her father [mother/ usual babysitter] a few weeks ago. The incident occurred when she was home alone with her father [mother/ babysitter, a 20-year-old college student named Mary/Mark, who babysat frequently], one night when her mother [father/father and mother] had to work late. Her dad came into her bedroom to tuck her in bed and say goodnight. This was their typical routine. On this night, her dad pulled the sheets off of her and put his hands on [removed] her underwear. He knelt beside her bed and rubbed her vagina [penis] through her underwear [put his mouth on her vagina/his penis]. Helen told her therapist that "he was doing something to my private parts for a very long time." When the therapist asked Helen to guess how long her father was hurting her, Helen replied "About 10 minutes." After a while he stopped rubbing [put her underwear back on], tucked her in bed, and said goodnight. He also told her not to tell anyone about this. Helen told her therapist that this was the first time anything like this had happened. After Helen disclosed this incident to her therapist, her therapist advised her that she and her mom [dad/parents] should file abuse charges against her father [mother/babysitter].

Physical abuse condition. The italicized portion above was replaced with the following: Her dad pulled the sheets off of her when she complained about having trouble going to sleep. He took off his belt, rolled her onto her stomach and beat her until she hurt all over. Helen told her therapist that "he was beating me with the belt for a very long time."

Note. Alternate versions are in brackets. The names and pronouns of the protagonists were changed across conditions to avoid repetition.

\section{Materials}

Materials for this study included 24 one-paragraph vignettes, each depicting a single occurrence of potential child abuse (see Table 1 for a sample vignette). Each incident described an 8-year-old child (boy or girl) who was left home alone with an adult (male or female, either a parent or babysitter). The choice to portray an 8-year-old victim was based on prior research demonstrating that an 8-year-old victim was more believable than younger (age 3) or older (age 13) victims (Key, Warren, \& Ross, 1996). The adult perpetrator abused the child for about 10 minutes and then warned the child not to tell anyone. The child's parents sent him or her to a psychotherapist because the child had been moody, and they were concerned. The abuse involved fondling (mild sexual abuse), oral copulation (severe sexual abuse; the terms "mild" and "severe" are meant purely in a relative sense), or being beaten with a belt (physical abuse). Each vignette stated that the abuse was disclosed during the child's psychotherapy session. Upon hearing the claim of abuse, the therapist advised that abuse charges should be filed.

\section{Procedure}

Undergraduates met individually with a research assistant to participate in an experiment on understanding perceptions of abuse involving child victims. Upon providing written consent, participants received two questionnaire packets, one for the participant to complete and the other to be completed by a non-student, aged 19 or older. The two packets contained instructions for the student or non-stu- 
dent, the questionnaire, and a debriefing sheet. Participants were asked to read the 24 vignettes (presented in one of two orders) and answer six questions following each vignette. The questions involved rating each abuse claim on 7 -point scales (e.g., $1=$ not at all traumatic to $7=$ extremely traumatic) along the following dimensions: how traumatic the incident was for the child (trauma), the severity of the abuse (severity), the likelihood that this type of incident occurs in society in general (likelihood of general occurrence), the likelihood that this type of incident would reoccur with this child and adult (likelihood of reoccurrence), how truthful the disclosure was (believability of the victim), and the probability that the victim would repress the memory of the abuse (repressibility). Trauma and severity, although significantly correlated, were both included in order to assess participants' intuitive understanding of these constructs, which were conceptualized as falling at different points on a continuum of subjectivity (i.e., trauma, reflecting more the subject's individual response) to objectivity (i.e., severity, reflecting more an observer's external appraisal). Finally, they were asked to rate, on a 7point scale, how credible they found claims of repressed/recovered memories of abuse.

Participants were instructed to complete the questionnaire, which was designed to take 15-30 minutes, in a quiet setting. Student participants were informed that to receive extra course credit, they needed to return both completed questionnaires within a 1-week period. Participants were allowed to take the materials home in order to increase the response rate and facilitate the recruitment of nonstudent participants (Fulero \& Finkel, 1991). To ensure confidentiality, no identifying information was collected on the questionnaires. However, non-student participants provided contact information on a separate sheet of paper. A subset of the sample was contacted via telephone to ensure that participants had completed the questionnaire themselves, all of whom provided verification.

\section{Data analysis}

The principal analysis was a $2 \times 2 \times 2 \times 3$ repeated-measures MANOVA, with the within-subject variables of victim's gender, perpetrator's gender, relationship, and type of abuse; participant type (student vs. non-student) and gender were also included as between-groups factors. The 6 dependent variables were the ratings, for each vignette, of perceived trauma, severity of abuse, likelihood of general occurrence, likelihood of reoccurrence, believability of the victim, and repressibility. Given the large number of specific directional hypotheses in the multivariate and follow-up univariate tests and to minimize Type II error, *was set at .01.

\section{Results}

The multivariate test showed a significant main effect of participant gender, $F(6,179)=5.97$, but not of participant type, $F(6,179)=1.76$. With regard to the within-subject manipulations, there were significant main effects of victim's gender, $F(6,179)=3.19$; perpetrator's gender, $F(6,179)=13.57$; relationship, $F(6,179)=7.81$; and abuse type, $F(12,173)=11.94$. There were also a number of significant interactions (i.e., 18 significant two-way interactions), which are explored in the univariate analyses presented below.

Only 17 of 252 (6.75\%) higher-order (three-way and higher) interactions were statistically significant at the .01 level. As no higher-order interactions were hypothesized and they would not be readily interpretable, we discuss only two-way interactions as well as significant main effects; when a main effect is better accounted for by the presence of a significant interaction, we describe the main effects only briefly and focus on interpreting the interactions. 


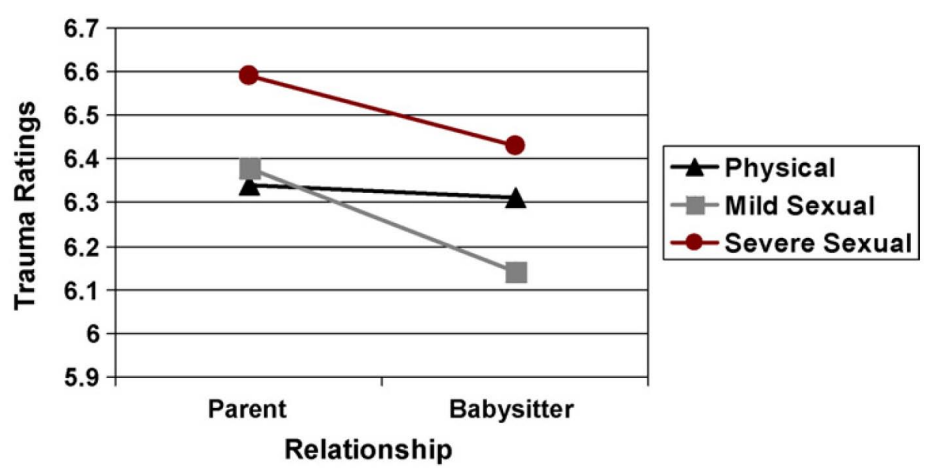

Figure 1. Interaction between abuse type and relationship on trauma ratings (Y-axis does not reflect the full scale).

\section{Trauma}

Main effects: Several significant main effects emerged for perceptions of how traumatic the abuse was for the victim, including victim's gender, $F(1,184)=8.80, M S E=.394$; perpetrator's gender, $F(1,184)=39.72, M S E=.535$; relationship, $F(1,184)=14.32, M S E=1.011$; and abuse type, $F$ $(2,368)=10.40, M S E=1.791$. Each of these main effects is better accounted for by the presence of a significant interaction.

Interactions: Perceptions of trauma showed an interaction between abuse type and relationship, $F$ $(2,368)=6.70, M S E=.517$ (Figure 1). Specifically, the nature of the relationship did not have an effect in the case of physical abuse; but sexual abuse, whether mild or severe, was perceived as significantly more traumatic when committed by a parent $(M \mathrm{~s}=6.37$ and 6.59 , respectively) than a babysitter $(M \mathrm{~s}=6.13$ and 6.43 , respectively). In addition, perpetrator gender interacted with two variables: victim, $F(1,184)=9.38, M S E=.476$, and participant gender, $F(1,184)=8.44$. The perpetrator gender by victim gender interaction indicated that the effect of victim gender was significant when the perpetrator was female ( $M \mathrm{~s}=6.35$ for female vs. 6.25 for male victims) but not when the perpetrator was male. In particular, the abuse was perceived as least traumatic when it involved a female perpetrator and a male victim. The perpetrator's gender had a significant effect on both male $(M \mathrm{~s}=6.35$ for male perpetrators and 6.12 for female perpetrators) and female participants ( $M \mathrm{~s}=6.47$ and 6.38 , respectively) but was larger for males.

\section{Severity}

Main effects: Participants' severity ratings closely paralleled their trauma ratings. Perceptions of how severe the abuse was were affected by perpetrator's gender, $F(1,184)=31.44, M S E=.598$; relationship, $F(1,184)=22.02, M S E=.754$; abuse type, $F(2,368)=17.38, M S E=2.253$; and participant gender, $F(1,184)=37.26$. Victim's gender, $F(1,184)=9.28, M S E=.352$, a significant main effect not accounted for by an interaction, revealed that participants viewed the abuse as more severe for female $(M=6.21)$ than male victims $(M=6.15)$.

Interactions: These main effects, with the exception of victim's gender, were qualified by several interactions. As with the trauma ratings, there were significant interactions between perpetrator and 


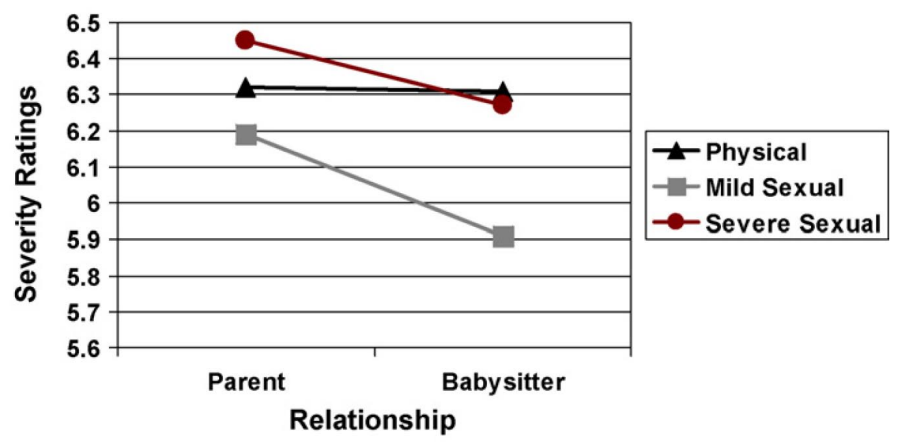

Figure 2. Interaction between abuse type and relationship on severity ratings (Y-axis does not reflect the full scale).

participant gender, $F(1,184)=8.03$. Men were affected more by the perpetrator's gender $(M \mathrm{~s}=6.13$ for male perpetrators and 5.93 for female perpetrators) than were women $(M \mathrm{~s}=6.36$ and 6.28 , respectively), although the effect was significant for both groups.

Perpetrator gender also interacted with abuse type, $F(2,368)=6.30, M S E=.402$, and relationship, $F$ $(1,184)=10.97, M S E=.244$. Physical abuse was perceived as roughly equally severe whether committed by a male or female; but sexual abuse, whether mild ( $M \mathrm{~s}=6.14$ vs. 5.96$)$ or severe ( $M \mathrm{~s}=6.42$ vs. 6.30), was perceived as significantly more severe when perpetrated by a male. The relationship by perpetrator gender interaction indicated that the effect of perpetrator gender was greater when the abuser was the babysitter ( $M \mathrm{~s}=6.24$ for the male perpetrator vs. 6.09 for the female perpetrator) than when it was the parent $(M \mathrm{~s}=6.35$ vs. 6.28 , respectively), although it was statistically significant in both conditions.

Finally, relationship interacted with abuse type, $F(2,368)=10.89, M S E=.598$. Mirroring the trauma ratings, the nature of the relationship exerted no effect in the case of physical abuse; but sexual abuse, whether mild or severe, was perceived as more severe when committed by a parent $(M \mathrm{~s}=6.19$ and 6.44, respectively) than a babysitter $(M \mathrm{~s}=5.91$ and 6.27, respectively; Figure 2).

\section{Likelihood of general occurrence}

Main effects: Participants' perceptions of how likely it is that a certain type of abuse occurs in society in general were affected by the perpetrator's gender, $F(1,184)=64.66, M S E=1.750$; the relationship, $F(1,184)=9.58, M S E=1.473$; and the type of abuse, $F(2,368)=56.31, M S E=1.628$.

Interactions: Perpetrator gender interacted significantly with both victim gender, $F(1,184)=11.00$, $M S E=.762$, and relationship, $F(1,184)=8.14, M S E=.641$. Specifically, females $(M=4.24)$ were perceived as more likely to be victims than males $(M=4.07)$ when the perpetrator was male; whereas there was no effect of victim gender when the perpetrator was female. In addition, the relationship had no effect on perceived likelihood of abuse when the perpetrator was female; but when the perpetrator was male, abuse committed by a father was seen as significantly more common $(M=4.26)$ than abuse committed by a babysitter $(M=4.05)$.

There was also a significant interaction between abuse type and relationship, $F(2,368)=50.78$, $M S E=1.163$, which revealed that the perceived likelihood of different kinds of abuse depended on who the perpetrator was. Physical abuse was rated more common for a parent $(M=4.54)$ than a babysitter $(M=3.90)$, but severe sexual abuse was rated more common for a babysitter $(M \mathrm{~s}=3.76$ vs. 


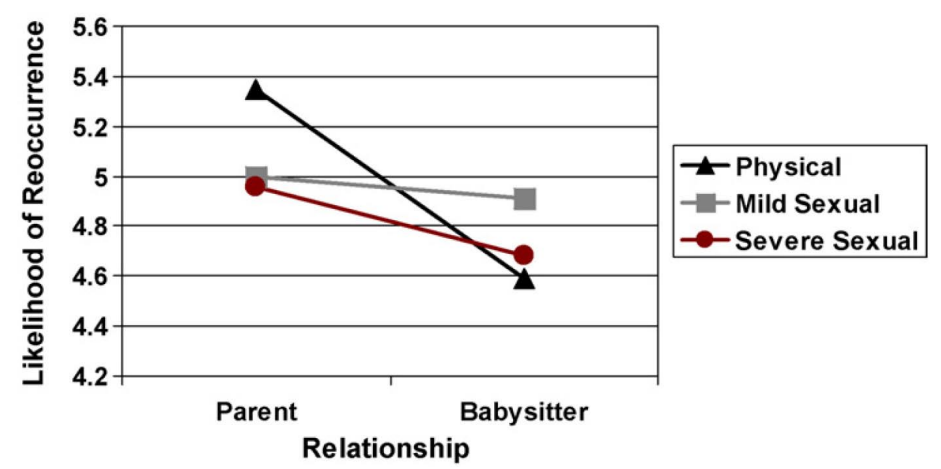

Figure 3. Interaction between abuse type and relationship on likelihood of reoccurrence ratings (Y-axis does not reflect the full scale).

3.64). Relationship did not significantly affect judgments regarding mild sexual abuse $(M \mathrm{~s}=4.01$ for babysitter vs. 3.90 for parent).

\section{Likelihood of reoccurrence}

Main effects: Participants' perceptions of how likely it was that the same type of abuse would reoccur were affected by the perpetrator's gender, $F(1,184)=28.09, M S E=1.656$; the relationship, $F$ $(1,184)=21.26, M S E=5.131$; and the type of abuse, $F(2,368)=5.81, M S E=1.621$. Participants' gender, $F(1,184)=24.63$, a significant main effect not better accounted for by an interaction, revealed that female participants believed that abuse was more likely to reoccur $(M=5.26)$ than did male participants $(M=4.15)$.

Interactions: There were interactions for likelihood of reoccurrence for perpetrator gender by victim gender, $F(1,184)=10.06, M S E=.728$; perpetrator gender by relationship, $F(1,184)=18.93$, $M S E=.791$; and abuse type by relationship, $F(2,368)=28.91, M S E=1.246$. The perpetrator gender by victim gender interaction mirrored that for the likelihood of general occurrence of abuse. Reoccurrence was judged more likely for heterosexual than homosexual abuse, for male ( $M \mathrm{~s}=5.11 \mathrm{vs}$. 4.96, respectively) but not for female perpetrators. The abuse was judged significantly more likely to reoccur when it was perpetrated by a male than by a female regardless of the relationship, but this effect of perpetrator gender was greater for a parent $(M s=5.28$ vs. 4.92$)$ than a babysitter $(M s=4.81$ vs. 4.66$)$. The abuse type by relationship interaction indicated that when the abuse was committed by a babysitter, mild sexual abuse was judged more likely to reoccur $(M=4.91)$ than either severe sexual abuse $(M=4.68)$ or physical abuse $(M=4.59)$, which did not differ from one another; however, when it was committed by a parent, physical abuse was judged more likely to reoccur $(M=5.35)$ than either mild $(M=5.00)$ or severe sexual abuse $(M=4.96$; see Figure 3$)$, which did not differ from one another.

\section{Victim believability}

Main effects: The victim's believability was affected by the type of abuse, $F(2,368)=8.36$, $M S E=1.793$, and participants' gender, $F(1,184)=17.86$. In addition, the victim was viewed as being more believable when the perpetrator was male $(M=5.85)$ than female $(M=5 \cdot 70), F(1,184)=19.21$, $M S E=1.055$. 


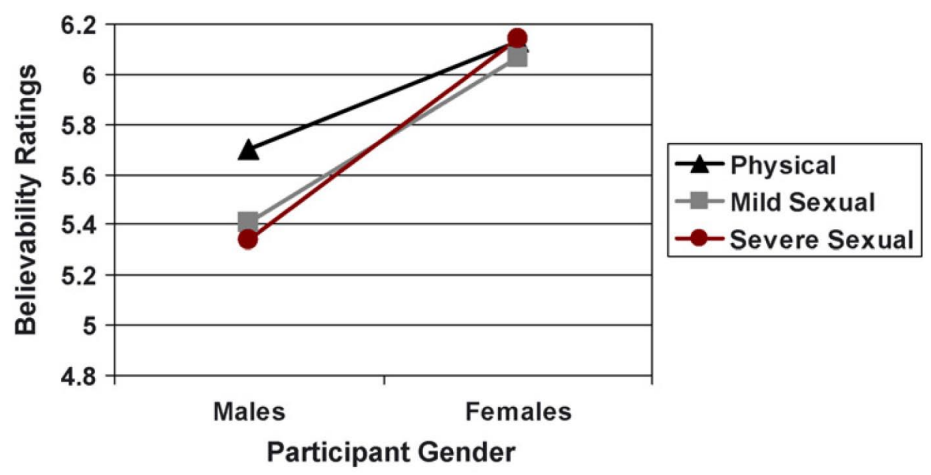

Figure 4. Interaction between abuse type and participant gender on victim believability ratings (Y-axis does not reflect the full scale).

Interactions: Abuse type interacted significantly with participant gender, $F(2,368)=7.01$, as well as relationship, $F(2,368)=5.20, M S E=.571$. The abuse type by gender interaction reflected greater differences in perceived believability across abuse types among males than females (see Figure 4). Posthoc comparisons showed that males rated physical abuse as more believable than severe sexual abuse, with mild sexual abuse intermediate and not significantly different from either of the other conditions; whereas females rated the victim as highly believable in all conditions. The abuse type by relationship interaction showed that a victim alleging physical abuse was more believable when it involved a parent $(M=6.06)$ than a babysitter $(M=5.89)$; relationship did not affect believability ratings for the other kinds of abuse.

\section{Repressibility}

Main effects: Perceptions of how likely it was that the child would repress the incident were affected by the perpetrator's gender, $F(1,184)=7.64, M S E=.797$. Also significant was the type of abuse, $F$ $(2,368)=10.47, M S E=2.821$, wherein participants rated repression as most likely in cases of severe sexual abuse $(M=3.64)$, followed by mild sexual abuse $(M=3.59)$ and physical abuse $(M=3.34)$.

Interactions: The only significant interaction was between victim and perpetrator gender, $F$ $(1,184)=11.21, M S E=.956$. Consistent with the trauma ratings, the effect of victim gender was significant when the perpetrator was female ( $M \mathrm{~s}=3.53$ for female vs. 3.42 for male victims) but not when the perpetrator was male. In particular, the abuse was seen as least repressible when it involved a female perpetrator and a male victim.

\section{Correlational analyses}

Given the large number of possible correlations and the exploratory nature of some of these analyses, we provide a broad overview of several correlations of interest. For these analyses, Pearson's correlations were conducted, with *set at .01. Perceptions of trauma and severity were significantly correlated for all 24 vignettes ( $r$ s ranged from .37 to .81). Contrary to our hypothesis, perceptions of repressibility were not significantly correlated with trauma or severity level for any of the vignettes. Perceptions of how common a certain manner of abuse is in general were significantly correlated with perceptions 
of how likely it would be to reoccur with the same individuals for all 24 vignettes ( $r$ s ranged from .25 to .47). Perceptions of the victim's believability were significantly and positively correlated with both trauma and severity ratings for 21 of the 24 vignettes. Thus, overall, the more severe and traumatic participants perceived the abuse to be, the more likely they were to believe the victim. Believability ratings were also positively correlated with ratings of the likelihood of reoccurrence for 22 vignettes and with ratings of the likelihood of occurrence for 11 vignettes. In other words, the more believable the victim seemed, the more participants expected that he or she would be abused again in the future and, to a lesser extent, that that kind of abuse happened in general. Believability ratings were not correlated with repressibility ratings for any of the 24 vignettes.

\section{Discussion}

Participants' perceptions of different kinds of abuse were affected to some extent by all of the manipulated variables and participant gender. For example, sexual abuse (whether mild or severe) was rated as being more traumatic and severe if perpetrated by a parent than by a babysitter. Significant perpetrator gender by victim gender interactions indicated that homosexual abuse was perceived as more traumatic and repressible than heterosexual abuse, but as less likely to occur; and male participants tended to be more affected by the gender of the perpetrator and abuse type than female participants. Many findings supported our hypotheses, but others were unexpected. The following sections-which include discussions of both main effects and interactions-address the impact of each variable on participants' perceptions of abuse.

\section{Participant characteristics}

The main effects were largely stable across participant type and gender, although females perceived the abuse as more severe and more likely to reoccur, and they were also more believing of abuse victims. This gender difference is consistent with previous literature showing that female mock jurors find sexual abuse victims more credible than male mock jurors and are more likely to convict (e.g., Golding, Sego, Sanchez, \& Hasemann, 1995; McCauley \& Parker, 2001). It is also consistent with some literature examining perceptions of physical abuse (Kean \& Dukes, 1991). The present findings offer a possible explanation for this effect, as they suggest that females and males process the same evidence differently; that is, women perceive a particular abusive act as more severe. In abuse cases, the perceived severity of the perpetrator's actions can be central to the determination of whether a crime took place and the incident's disposition (Hetherton \& Beardsall, 1988), as opposed, say, to inappropriate (but non-criminal) touching.

Participant gender interacted with perpetrator gender (on trauma and severity) and with abuse type (on believability), with men influenced more by the manipulations. Participant type was not significant in the overall MANOVA, so it was not examined in the univariate analyses. There are many valid arguments for why research findings based solely on student participants should be interpreted cautiously (e.g., Sears, 1986), but the present findings suggest that student participants are an acceptable sample from which to generalize in this kind of research.

\section{Victim gender}

As predicted, the abuse of females was perceived as more severe and traumatic. However, these perceptions were not associated with a perception that female victims were more believable or more likely 
to repress their memory of abuse. Contrary to our hypothesis, the abuse of females was not perceived as more common in general, nor were the particular types of abuse viewed as more likely to reoccur when they involved a female victim. This is surprising, as the literature shows overwhelmingly that females are more likely to be abused than males, at least sexually (USDHHS, 2006). Participants' judgments suggest that they were unaware of this gender difference in the incidence of abuse, which may reflect a growing realization that sexual abuse of males is more common than previously thought (Romano \& De Luca, 2001), as well as recent media attention given to same-sex abuse reports within the Catholic Church. Although victim gender exerted few main effects, it did interact with perpetrator gender, as described below.

\section{Perpetrator gender}

Abuse by a male was perceived as more traumatic, severe, and repressible; more likely to occur in general and to reoccur in a specific instance; and it made the victim seem more believable. Several of these judgments were qualified by interactions with the other variables, especially victim gender. Specifically, in a victim gender by perpetrator gender interaction, heterosexual abuse was perceived as more common, and more likely to reoccur, than homosexual abuse; this perception accurately reflects demographic data for male perpetrators, though less so for female perpetrators (Rudin et al., 1995). As hypothesized, there was also a tendency for homosexual abuse to be seen as more traumatic, and more likely to be repressed, than heterosexual abuse, especially in the case of a male victim. The belief that abuse of a boy by a woman, especially when it is of a sexual nature, is less serious than abuse involving other gender constellations is a common one (e.g., Dollar et al., 2004); however, there is an absence of data indicating different psychological sequelae for homosexual versus heterosexual abuse (KendallTackett et al., 1993).

\section{Type of abuse}

Participants were responsive to variations in the type of abuse. Consistent with actual incidence data (USDHHS, 2006), participants perceived physical abuse as most likely to occur and reoccur, followed by mild sexual, then severe sexual abuse. Physical abuse victims were most believable, followed by sexual abuse victims, who did not differ much as a function of the degree of sexual abuse. It is worth noting that the victim was fairly believable for all types of abuse (means ranged from 5.69 to 5.90 on a 7-point scale), perhaps reflecting the absence of any information in the vignettes that controverted the victim's account. As predicted, severe sexual abuse was perceived as most traumatic, most likely to be repressed, and very severe. Thus, participants appeared to agree with both the evidence showing more harmful effects for more severe abuse (Kendall-Tackett et al., 1993) and the popular Freudian notion that the more severe an event, the more likely it is to be repressed (Erdelyi, 1985). As described below, the type of abuse also interacted with the relationship between victim and perpetrator.

\section{Relationship}

As predicted, participants perceived parental abuse to be more traumatic and severe than abuse perpetrated by a babysitter, although not as more repressible. Consistent with demographic data (USDHHS, 2006 and Rudin et al., 1995), they also perceived parental abuse as more common and more likely to reoccur. The relationship between victim and perpetrator interacted most often with type of abuse, with the main division occurring between physical abuse and the two types of sexual abuse. 
Specifically, the effect of relationship on perceived trauma and severity existed only for sexual abuse; physical abuse was perceived as equally severe whether perpetrated by a parent or a babysitter. With respect to perceived occurrence, parents were viewed as more likely than babysitters to commit physical abuse, but babysitters were seen as more likely to commit severe sexual abuse. This impression does not comport with data showing that parents most frequently perpetrate sexual abuse (e.g., USDHHS, 2006).

\section{General themes and relationships among variables}

Trauma/severity/repressibility: Ratings of trauma, severity, and believability were highly intercorrelated. In other words, participants seemed to find victims of more serious abuse more credible, and to assume that they would be less likely to fabricate. Perceptions of the victim repressing the abuse were somewhat, but not very, likely overall, with means across conditions between 3.0 and 4.0 (on a 7-point scale). This is consistent with Golding, Sanchez, and Sego's (1996) finding that survey respondents were somewhat believing of repression, but were not wholly accepting of it either. Contrary to our hypothesis, perceived repressibility was not correlated with perceived trauma or severity for any of the 24 vignettes; this perceived lack of a relationship runs counter to the popular Freudian notion.

Consistent with previous studies (e.g., Dollar et al., 2004), several themes also emerged when examining the pattern of significant interactions. Specifically, interactions between perpetrator and victim gender indicated that participants viewed the female perpetrator/male victim scenario as the least traumatic and repressible. In addition, male participants' ratings of trauma and severity were more affected by the perpetrator's gender than female participants' ratings. Finally, abuse type by relationship interactions revealed that participants viewed sexual abuse (in contrast to physical abuse) as more traumatic and severe if committed by a parent.

Occurrence/reoccurrence: Perceptions of how likely a certain kind of abuse was to occur in general were significantly correlated with perceptions of how likely it was to reoccur in a given instance, showing a sensitivity to population base rates. Participants also demonstrated this sensitivity in adjusting their ratings as a function of the manipulated variables. With the exception of victim gender (i.e., they did not judge that females were more commonly victims than males), they correctly judged that males perpetrate most kinds of abuse more often than females; that heterosexual abuse (at least by male perpetrators) is more common than homosexual abuse; that physical abuse is more common than mild sexual abuse, which in turn is more common than severe sexual abuse; and that parents commit physical abuse more often than babysitters.

Victim believability: Victims who were perceived as more traumatized or as having suffered more severe abuse were more believable. This likely reflects a tendency to expect less fabrication of more extreme claims of abuse.

\section{Limitations and future directions}

Although the vignettes utilized in the current study were similar to those used in other studies (e.g., Broussard et al., 1991 and Dollar et al., 2004), there are some methodological limitations that warrant discussion. For example, all study participants responded to each of the 24 vignettes. Thus, it is possible that the participants' responses were affected by demand characteristics. Specifically, because only slight details (e.g., gender) were changed across vignettes and because participants responded 
to all scenarios in a relatively quick amount of time (15-30 minutes), it is possible that participants were able to intuit the hypotheses in question (deducing the study's aims) and respond accordingly. Although plausible, our findings are in line with results from other vignette studies, many of which have used a between-subjects design. Thus, although these results must not be overinterpreted, the study design does not seem to have precluded outcomes consistent with past research. A second limitation is that although it is a relatively common practice in vignette research, the use of single-item dependent measures to operationalize broad constructs (e.g., perceived trauma) may limit generalizability.

A third limitation concerns the nature of the sample (e.g., predominantly women), which may also restrict the generalizability of the findings. Although the sample included students and non-students, we did not assess the relationship between the student participant and the non-student he or she brought to the study. Future research should examine the similarities and differences between the student/non-student pairs. Further, although the current study represents an initial step in examining perceptions related to multiple forms of maltreatment rather than focusing solely on sexual abuse, this study included only one (and a relatively severe one, at that) representation of physical abuse. In order better to compare and contrast perceptions based on abuse type, future studies should include comparable "levels"-both mild and severe-of each type of abuse. The present findings might not generalize to other memory recovery contexts (e.g., "spontaneous" recovery not part of psychotherapy), although prior research on this point has yielded few differences (e.g., Faimon, O’Neil, \& Bornstein, 2005). It also may be useful for future studies to examine explicitly potential differences that emerge not only between same- and opposite-sex vignettes but within different combinations of homosexual or heterosexual abuse (e.g., male-on-female vs. female-on-male).

\section{Conclusions and implications}

In addition to providing support for continued research on people's perceptions of multiple forms of child maltreatment, findings from this empirical paradigm-particularly the emergence of significant interactions between variables-shed light on the complexity of these relationships and have both clinical and forensic implications. In this study, for example, participants perceived sexual abuse (whether mild or severe) to be more traumatic and severe when committed by a parent and, in scenarios involving a male perpetrator, as more common and likely to reoccur when committed by the father than the babysitter. Consistent with past studies (e.g., Dollar et al., 2004), participants also attributed the least trauma to scenarios involving a female perpetrator and a male victim. Also in line with previous research (e.g., Dollar et al., 2004 and Smith et al., 1997), male participants tended to be more affected by the gender of the perpetrator than female participants.

From a clinical perspective, the clinician's own beliefs about how severe, traumatic, or repressible various kinds of abuse are can influence intervention and treatment with abuse victims. As other studies have shown (e.g., Hetherton \& Beardsall, 1988), mental health workers are not exempt from bias and must assess critically their own perceptions in order to work effectively with clients. Treatment can also benefit from the clinician's understanding of how people in general perceive different kinds of abuse, as it can sensitize the therapist to the ways in which others-such as teachers, peers, or family members-might perceive and react to a child's disclosure of abuse. These reactions can play a significant role in the child's interactions with support providers and subsequent adjustment (Denov, 2003; Hicks \& Tite, 1998).

Child maltreatment varies along a number of dimensions (e.g., type of abuse, victim and perpetrator characteristics). From a legal perspective, perceptions of abuse characteristics can influence the in- 
vestigation and disposition of cases, as well as jury verdicts. In showing that perceptions of abuse vary as a function of factors such as victim and perpetrator gender, abuse type, and victim-perpetrator relationship, the present study highlights the importance of understanding people's expectations regarding different kinds of abuse. Stereotypes about abuse influence child protection professionals' reaction to incidents of potential abuse (Hetherton \& Beardsall, 1988), and the same is true of jurors, whose expectations influence their verdicts (Bornstein \& Rajki, 1994; Smith, 1993). A greater awareness of people's stereotypes and expectations about abuse will help abuse victims as they interact with others in these various contexts.

\section{Acknowledgements}

We thank Alexis Luce for assistance in data collection and David DiLillo for helpful comments on the manuscript.

\section{References}

Ashton, $2004-$ V. Ashton, The effect of personal characteristics on reporting child maltreatment, Child Abuse \& Neglect $\mathbf{2 8}$ (2004), pp. 985-997.

Back and Lips, 1998 - S. Back and H. M. Lips, Child sexual abuse: Victim age, victim gender and observer gender as factors contributing to attributions of responsibility, Child Abuse \& Neglect 22 (1998), pp. 1239-1252.

Bornstein and Muller, 2001 - B. H. Bornstein and S. Muller, The credibility of recovered memory testimony: Exploring the effects of alleged victim and perpetrator gender, Child Abuse \& Neglect 25 (2001), pp. 1415-1426.

Bornstein and Rajki, 1994 - B. H. Bornstein and M. Rajki, Extra-legal factors and product liability: The influence of mock jurors' demographic characteristics and intuitions about the cause of an injury, Behavioral Sciences and the Law 12 (1994), pp. 127-147.

Bottoms and Goodman, 1994 - B. L. Bottoms and G.S. Goodman, Perceptions of children's credibility in sexual assault cases, Journal of Applied Social Psychology 24 (1994), pp. 702-732.

Broussard et al., 1991 - S. Broussard, W. G. Wagner and R. Kazelskis, Undergraduate students' perceptions of child sexual abuse: The impact of victim sex, perpetrator sex, respondent sex, and victim response, Journal of Family Violence 6 (1991), pp. 267-278.

Clark and Nightingale, 1997 - H. L. Clark and N. N. Nightingale, When jurors consider recovered memory cases: Effects of victim and juror gender, Journal of Offender Rehabilitation 25 (1997), pp. 87-104.

Cupoli and Sewell, 1988 - J. M. Cupoli and P. M. Sewell, One thousand fifty-nine children with a chief complaint of sexual abuse, Child Abuse \& Neglect 12 (1988), pp. 151-162.

Denov, 2003 - M. S. Denov, To a safer place? Victims of sexual abuse by females and their disclosures to professionals, Child Abuse \& Neglect 27 (2003), pp. 47-61.

DeRoma et al., 1997 - V. M. DeRoma, D. J. Hansen, A. C. Tishelman and P. D’Amico, Influence of information related to child physical abuse on professional ratings of adjustment and prognosis, Child Abuse \& Neglect 21 (1997), pp. 295-308.

Dollar et al., 2004 - K. M. Dollar, A. R. Perry, M. E. Fromuth and A. R. Holt, Influence of gender roles on perceptions of teacher/adolescent student sexual relations, Sex Roles 50 (2004), pp. 91-101.

Dukes and Kean, 1989 - R. L. Dukes and R. B. Kean, An experimental study of gender and situation in the perception and reportage of child abuse, Child Abuse \& Neglect 13 (1989), pp. 351-360.

Elstein, 1988 - A. S. Elstein, Cognitive processes in clinical inference and decision making. In: D. Turk and P. Salovey, Editors, Reasoning, inference and judgment in clinical psychology, Free Press, New York (1988), pp. 17-50.

Erdelyi, 1985 - M. H. Erdelyi, Psychoanalysis: Freud's cognitive psychology, Freeman, New York (1985).

Faimon et al., 2005 - B. Faimon, K. O’Neil and B. H. Bornstein, Recovered memory at trial: Effects of abuse type and manner of recovery. In: L.M. Stoneham, Editor, Advances in sociology research 2, Nova Science, Hauppauge, NY (2005), pp. 233-251.

Faller, 1987 - K. C. Faller, Women who sexually abuse children, Violence and Victims 2 (1987), pp. 263-276.

ForsterLee et al., 1999 - R. ForsterLee, I. A. Horowitz, R. Ho, L. ForsterLee and A. McGovern, Community members' perceptions of evidence: The effects of gender in a recovered memory civil trial, Journal of Applied Psychology 84 (1999), pp. 484-495. 
Fulero and Finkel, 1991 - S. M. Fulero and N. J. Finkel, Barring ultimate issue testimony, Law and Human Behavior 15 (1991), pp. 495-507.

Golding et al., 2003 - J. M. Golding, H. M. Fryman, D. F. Marsil and J. A. Yozwiak, Big girls don’t cry: The effect of child witness demeanor on juror decisions in a child sexual abuse trial, Child Abuse \& Neglect 27 (2003), pp. 1311-1321.

Golding et al., 1996 - J. M. Golding, R. P. Sanchez and S. A. Sego, Do you believe in repressed memories?, Professional Psychology: Research and Practice 27 (1996), pp. 429-437.

Golding et al., 1995 - J. M. Golding, S. A. Sego, R. P. Sanchez and D. Hasemann, The believability of repressed memories, Law and Human Behavior 19 (1995), pp. 569-592.

Hetherton and Beardsall, 1988 - J. Hetherton and L. Beardsall, Decisions and attitudes concerning child sexual abuse: Does the gender of the perpetrator make a difference to child protection professionals?, Child Abuse \& Neglect 22 (1988), pp. 1265-1283.

Hicks and Tite, 1998 - C. Hicks and R. Tite, Professionals' attitudes about victims of child sexual abuse implications for collaborative child protection teams, Child and Family Social Work 3 (1998), pp. 37-48.

Kean and Dukes, 1991 - R. B. Kean and R. L. Dukes, Effects of witness characteristics on the perception and reportage of child abuse, Child Abuse \& Neglect 15 (1991), pp. 423-435.

Kendall-Tackett et al., 1993 - K. A. Kendall-Tackett, L. M. Williams and D. Finkelhor, Impact of sexual abuse on children: A review and synthesis of recent empirical studies, Psychological Bulletin 113 (1993), pp. 164-180.

Key et al., 1996 - H. G. Key, A. R. Warren and D. F. Ross, Perceptions of repressed memories: A reappraisal, Law and Human Behavior 20 (1996), pp. 555-563.

Kouyoumdjian et al., $2005-$ H. Kouyoumdjian, A. R. Perry and D. J. Hansen, The role of adult expectations on the recovery of sexually abused children, Aggression and Violent Behavior 10 (2005), pp. 475-489.

Lewis and Stanley, 2000 - C. F. Lewis and C. R. Stanley, Women accused of sexual offenses, Behavioral Sciences and the Law 18 (2000), pp. 73-81.

Maynard and Wiederman, 1997 - C. Maynard and M. Wiederman, Undergraduate students' perceptions of child sexual abuse: Effects of age, sex, and gender-role attitudes, Child Abuse \& Neglect 21 (1997), pp. 833-844.

McCauley and Parker, 2001 - M. R. McCauley and J. F. Parker, When will a child be believed? The impact of the victim's age and juror's gender on children's credibility and verdict in a sexual-abuse case, Child Abuse \& Neglect 25 (2001), pp. 523-539.

McDonald, 2005 - W. R. McDonald, Child maltreatment 2003, US Department of Health and Human Services, Washington DC (2005).

Nagel et al., 1997 - D. E. Nagel, F. W. Putnam, J. G. Noll and P. K. Trickett, Disclosure patterns of sexual abuse and psychological functioning at a 1-year follow-up, Child Abuse \& Neglect 21 (1997), pp. 137-147.

Romano and De Luca, 2001 - E. Romano and R. V. De Luca, Male sexual abuse: A review of effects, abuse characteristics, and links with later psychological functioning, Aggression and Violent Behavior 6 (2001), pp. 55-78.

Rudin et al., 1995 - M. M. Rudin, C. Zalewski and J. Bodmer-Turner, Characteristics of child sexual abuse victims according to perpetrator gender, Child Abuse \& Neglect 19 (1995), pp. 963-973.

Schmidt and Brigham, 1996 - C. W. Schmidt and J. C. Brigham, Jurors' perceptions of child victim-witnesses in a simulated sexual abuse trial, Law and Human Behavior 20 (1996), pp. 581-606.

Sears, 1986 - D. O. Sears, College sophomores in the laboratory: Influences of a narrow data base on social psychology's view of human nature, Journal of Personality and Social Psychology 51 (1986), pp. 515-530.

Sedlak and Broadhurst, 1996 - A. J. Sedlak and D. D. Broadhurst, Third national incidence study of child abuse and neglect: Final report, US Department of Health and Human Services, Washington, DC (1996).

Smith, 1993 - V. L. Smith, When prior knowledge and law collide: Helping jurors use the law, Law and Human Behavior $\mathbf{1 7}$ (1993), pp. 507-536.

Smith et al., 1997 - H. D. Smith, M. E. Fromuth and C. C. Morris, Effects of gender on perceptions of child sexual abuse, Journal of Child Sexual Abuse 6 (1997), pp. 51-63.

USDHHS, 2006 - US Department of Health and Human Services (USDHHS). (2006). Child maltreatment 2004. Washington, DC: US Government Printing Office. Retrieved September 7, 2006, from http://www.acf.hhs. gov/programs/cb/pubs/cmo4/.

Williams, 1994 - L. M. Williams, Recall of childhood trauma: A prospective study of women's memories of child sexual abuse, Journal of Consulting and Clinical Psychology 62 (1994), pp. 1167-1176. 